\title{
Chimeric Antigen Receptors for Cancer: Progress and Challenges
}

\author{
Adrienne H. Long ${ }^{1,2} \cdot$ Daniel W. Lee $^{2} \cdot$ Crystal L. Mackall ${ }^{2}$
}

Published online: 7 October 2015

(C) Springer International Publishing AG (outside the USA) 2015

\begin{abstract}
Chimeric antigen receptors (CARs) genetically link an antigen-binding domain with cell-signaling domains to redirect immune cell specificity toward antigens expressed on the surface of cancer cells. Progress in CAR engineering over the last two decades has elucidated fundamental principles impacting CAR potency, and today CARs can be readily generated toward essentially any cell surface target on cancer cells. Efficacy thus far has been most impressive using CD19-CAR expressing T cells to treat B cell lymphoblastic leukemia, although clear activity has also been observed using CD19-CARs in patients with chronic lymphocytic leukemic and B cell lymphoma. Much less data is available regarding CAR efficacy for solid tumors. Here, we summarize current concepts of CAR design, with a focus on the relationship between structure and function, a review of the clinical results reported thus far, and the challenges to be addressed in future studies.
\end{abstract}

This article is part of the Topical Collection on Cellular Therapies: Preclinical and Clinical

Crystal L. Mackall

mackallc@mail.nih.gov

Adrienne H. Long

longad@mail.nih.gov

Daniel W. Lee

leed3@mail.nih.gov

1 Feinberg School of Medicine, Northwestern University, Chicago, USA

2 Pediatric Oncology Branch, Center for Cancer Research, National Cancer Institute, National Institutes of Health, Bldg 10, Rm. 1W-3750, 10 Center Dr. MSC 1104, Bethesda, MD 20892, USA
Keywords Adoptive immunotherapy $\cdot$ Chimeric antigen receptors $\cdot$ Genetic engineering $\cdot \mathrm{T}$ cells $\cdot \mathrm{B}$ cell malignancies . Acute lymphoblastic leukemia

\section{Introduction}

Chimeric antigen receptors (CARs) are hybrid immune receptors that directly bind to antigen and initiate immune cell activation, degranulation, and cytokine release. Although CARs theoretically can be expressed on essentially any immune cell, the vast majority of work using CARs to redirect specificity has focused on T cells. In this context, the fundamental goal of CAR engineering is to link $\mathrm{T}$ cell signaling domains with MHC-independent antigen-binding domains. Thus, CARs eliminate the MHC-restriction traditionally associated with $\mathrm{T}$ cell recognition, while maintaining $\mathrm{T}$ cell potency and the capacity for long-lived immune responses. Optimizing these "designer receptors" to yield greater potency and specificity continues to be a major focus of investigation. This review will discuss fundamental aspects of CAR design, providing both a historical perspective as well as a vision toward the future. We will also review clinical results of CAR-based T cell immune therapies for the treatment of cancer and comment on challenges facing this nascent, but promising field.

\section{Principles of CAR Design}

\section{Antigen-Binding Domains}

The first chimeric receptor was reported in 1989 by Eshhar et al., who developed a receptor linking the variable domains of a monoclonal antibody ( $\mathrm{mAb}$ ) targeting trinitrophenyl to the constant regions of the TCR alpha and beta chains, which 
endowed transfectants with MHC-independent antigen specificity $[1,2]$. CAR potency was significantly increased in 1991 by incorporation of the TCR zeta chain as the signaling moiety in the receptor, in lieu of the TCR alpha or beta chains [3]. The first "modern CAR" was reported in 1993, which linked the potent TCR zeta signaling domain with a single chain variable fragment $(\mathrm{scFv})$ as the antigen-binding moiety [4]. scFvs are fusion proteins derived from $m A b s$ that covalently link heavy and light chain variable regions $\left(\mathrm{V}_{\mathrm{H}}\right.$ and $\left.\mathrm{V}_{\mathrm{L}}\right)$ via a flexible peptide linker. Thus, scFvs impart antigen specificity provided by both antibody heavy and light chains, but as a single peptide construct. Today, most CARs under study incorporate a $\mathrm{scFv}$ as the antigen-binding domain, though some investigators have also utilized ligands for receptors overexpressed by tumor cells as antigen-binding domains, most notably IL13 to target IL13R $\alpha 2+$ brain tumors [5-11].

Several properties of the antigen:antigen-binding domain interaction have been demonstrated to impact CAR efficacy including affinity to antigen [12-15], target epitope location [15-17], and target epitope density [12, 17]. In general, a threshold level of affinity is required for CAR activity. However, the relationship between affinity and efficacy is less clear for CARs than it is for soluble mAbs, as higher-affinity scFvs do not always provide improved CAR efficacy [14, 15]. Regarding target epitope location, several studies demonstrate that membrane-proximal epitopes are more effectively targeted via CARs than membrane-distal epitopes [15-17], again a distinction from principles of $\mathrm{mAb}$-based protein therapeutics. With regard to target epitope density, it is clear that antigen density above a minimum threshold is required for effective CAR activity. However, prediction of a universal threshold across antigens remains difficult, since the importance of other factors such as ScFv affinity and CAR expression levels is also impacted with changes in target epitope density. As discussed later, an improved understanding of the impact of target epitope density is critical for optimizing CAR therapy, both in terms of understanding the risks associated with low-level antigen expression on normal tissues and in addressing the problems of tumor resistance associated with antigen downregulation.

Recently, oligomerization of scFvs has been identified as a critical factor that can diminish the efficacy of CAR T cells through the induction of antigen-independent, tonic signaling $[18 \bullet \cdot$. Long et al. compared the efficacy of two distinct CARs, one targeting CD19 and a second targeting the GD2 ganglioside, against an engineered osteosarcoma line expressing both GD2 and CD19 antigens. Both CARs demonstrated equivalent killing ex vivo, whereas only the CD19-CAR reduced tumor size in vivo. T cells expressing the ineffective GD2-CAR in this study developed evidence of exhaustion early after transduction, which was not observed in T cells transduced with the CD19-CAR. Further studies revealed that the $\mathrm{scFv}$ incorporated into the GD2-CAR spontaneously aggregated on the surface of the transduced $\mathrm{T}$ cells, leading to antigen-independent signaling. Early exhaustion was also observed in T cells expressing CARs targeting Her2Neu and CD22, but was distinctly absent in T cells expressing the CD19-CAR. These results demonstrate that some cellassociated scFvs spontaneously aggregate, consistent with similar observations made historically by investigators studying scFv proteins [19-21]. Similar findings were also recently reported in CARs targeting c-Met and mesothelin, where constitutive signaling was associated with diminished functionality in xenograft models [22]. Thus, an emerging paradigm holds that a propensity for individual scFvs to induce spontaneous CAR signaling can adversely affect CAR function, and therefore such properties should be screened for early during CAR development.

Modulation of "spacer domains" represents another area of CAR design where emerging science demonstrates impressive effects on functionality. Spacer domains are frequently incorporated between the antigen-binding domain and transmembrane segment in order to improve accessibility to target antigens. Frequently, spacer domains take the form of immunoglobulin hinge and constant regions, but can also comprise extracellular domains from $\mathrm{CD} 28, \mathrm{CD} 8 \alpha$, or other proteins [23•]. An increasing number of reports suggest that the CAR spacer domains can significantly impact functionality of these synthetic receptors. Effective targeting of some antigens requires that CAR spacer length be optimized in order to obtain efficient lysis and cytokine production upon exposure to target cells. This is thought to be due to a need to achieve an ideal distance between the target cell and T cell membranes [13, 17, $24,25]$. However, the importance of optimizing spacer domain length does not appear to be universally required $[15$, 17]. Furthermore, recent reports have demonstrated that immunoglobulin-based spacer domains can negatively impact CAR efficacy in xenograft models [26, 27•]. In these studies, the $\mathrm{Fc} \gamma \mathrm{R} 1$ receptor on $\mathrm{Ly} 6 \mathrm{C}+$ myeloid cells in immunodeficient mice cross-linked CARs incorporating an $\mathrm{IgG}_{4} \mathrm{CH}_{2} \mathrm{CH}_{3}$ spacer domain, leading to $\mathrm{CAR} T$ cell activation-induced cell death in vivo and poor antitumor efficacy. These findings may have significant implications regarding the future design of CAR spacer domains, though the extent to which this phenomenon occurs in the immunocompetent host where Fc receptors are likely pre-occupied by circulating immunoglobulins remains to be seen.

\section{Costimulatory Signals}

T cells expressing "first generation" CARs, which incorporate a primary signaling domain without a costimulatory domain, showed some efficacy in early studies [28-36], though cytokine production and in vivo persistence of these CAR T cells were modest [32, 37-39]. Thus, "second generation" CARs were developed, which incorporate a costimulatory domain into the primary receptor, thereby providing the second signal 
necessary for complete $\mathrm{T}$ cell activation upon antigen binding. The most common costimulatory domains incorporated into second generation CARs have been CD28 or 4-1BB [40], though OX40 [41, 42], CD27 [43], ICOS [44] and FceRI $\gamma$ [23.] have also been described. To date, no comprehensive study has systematically compared the efficacy of CAR expressing $T$ cells bearing the entire range of known costimulatory domains, but numerous studies have shown that the addition of a costimulatory domain significantly enhances CAR T cell persistence and cytokine production in preclinical [45-51] and clinical trials [52•]. Thus, second generation CARs are the most common form currently being tested.

A recent study provided insight into qualitative distinctions between the CD28 and 4-1BB costimulatory domains on CAR T cell function. Using a GD2-specific CAR, which developed early exhaustion due to tonic, antigen-independent signaling, investigators observed that GD2-CAR T cells expressing the TCR zeta and the CD28 costimulatory domain had greater levels of T cell exhaustion than those incorporating TCR zeta alone $[18 \bullet \cdot$. In contrast, CAR T cells expressing TCR zeta and the 4-1BB costimulatory domain showed diminished exhaustion compared to GD2-CARs expressing CD28 endodomains. This study was the first to identify a potent anti-exhaustion effect of 4-1BB costimulation, which resulted in greater persistence of both CARs rendered exhausted due to tonic signaling (e.g., GD2-CARs), as well as those rendered exhausted by high levels of antigen (e.g., CD19-CARs transferred into leukemia bearing hosts). Thus, emerging concepts hold that investigators can selectively design CARs to be more persistent by incorporating a 4-1BB costimulatory domain, whereas CARs designed for short-term effects might be better suited with a CD28 costimulatory domain.

Some groups have also developed "third generation" CARs, which incorporate two costimulatory domains, though the data remains unclear as to whether additional costimulation enhances efficacy of CAR therapies [15, 41, $42,53,54]$. Indeed, some studies have demonstrated that excessive costimulation such as that provided by the "third generation" CARs is associated with diminished efficacy. Consistent with this model, recent work by Kunkele et al. demonstrated that augmentation of $\mathrm{T}$ cell activation via CAR signaling either by modifying spacer lengths or costimulatory domains may ultimately diminish CAR functionality due to the induction of activation-induced cell death [55]. Together, the data suggest a "goldilocks" phenomenon for CAR T cell activation, where underactivation or overactivation is equally undesirable, and where optimal functionality likely requires intermediate levels of activation.

\section{Next Generation CAR Engineering}

Tumor heterogeneity is a fundamental principle in oncology, and a corollary is that any therapeutic focused on one target is likely to ultimately be met with resistance due to selection of cells lacking the target of interest. CAR-based immunotherapy is no exception to this rule, and emerging data emanating from studies of CD19-CARs for the treatment of B cell acute lymphoblastic leukemia have demonstrated a substantial inci-

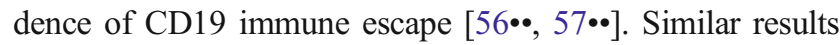
have also been observed following treatment with blinatumomab, the CD19/CD3 antibody-based bispecific engager [58]. Loss of expression of EGFRvIII has also been described on glioblastoma targeted with CAR T cells to that antigen. Thus, the development of effective cancer immunotherapies will likely require targeting of more than one antigen, and studies are underway to determine the best way to accomplish this in the context of CAR-based therapies.

The simplest approach to designing CAR therapies against two antigens is to utilize two populations of cells, each with specificity for one antigen. Proof-of-principle for this approach comes from studies by Hedge et al., wherein investigators demonstrated significant heterogeneity of Her2Neu and IL13R $\alpha 2$ expression among glioblastoma multiforme tumors at the time of resection, which was followed by the development of antigen loss variants following immune pressure mediated by CAR-modified T cells. Such evolution could be inhibited by simultaneous exposure to CARs targeting Her2 and IL13R $\alpha 2$ [59•]. Alternatively, gene constructs can be engineered to express two CARs on the surface of an individual T cell, and while this is feasible, expression of each CAR in this setting may not be optimal. Recently, tandem CARs have been reported, which incorporate two $\mathrm{scFv}$ antigenbinding domains into one receptor using Gly-Ser linkers $\left[59^{\bullet}, 60^{\bullet}\right]$. Given the prevalence of tumor heterogeneity and the emerging importance of antigen loss/immune escape in the context of immunotherapy, it is anticipated that studies of bivalent CARs and regimens incorporating CARs targeting multiple antigens will be a focus of intense study in the coming years.

Many groups are also focusing on novel strategies to enhance specificity of CARs toward cancer rather than normal tissues, in an effort to minimize on-target, off-tumor toxicity. To this end, inhibitory CARs (iCARs) have been recently described, which incorporate signaling domains of inhibitory receptors such as PD-1 and CTLA-4 [61]. Such models hold that $\mathrm{T}$ cells co-transduced with CARs specific for tumorantigens and iCARs specific for normal-tissue antigens would theoretically activate and degranulate only in the absence of normal tissue antigen, enhancing specificity for tumor. Other studies have attempted to restrict CAR T cell killing to cells concurrently expressing two tumor antigens. To date, this has been proposed by separating the $\mathrm{CD} 3 \zeta$ and costimulatory domains across two different CARs, in hopes the presence of both antigens will be required for full CAR T cell effector function [62•, 63]. Proof-of-principle studies have been reported, though it appears that risk remains if "inefficient" 
CARs with $\mathrm{CD} 3 \zeta$ signaling are rescued through exposure to costimulatory signaling within the inflamed tumor microenvironment. Furthermore, it also remains unclear to what extent such dual CAR T cells could be "licensed" at the tumor site where both antigens are present, and subsequently mediate on-target off-tumor toxicity in other compartments.

\section{CAR T Cells for B Cell Malignancies}

\section{Clinical Results}

The first clinical report of CD19-CAR T cells was published in 2010 and described a case of lymphoma regression and B cell depletion following infusion of CAR T cells [64]. Since that time, several groups have demonstrated activity of CD19directed CAR T cell therapies against a variety of B cell malignancies [56••, 57••, 65, 66, 67•]. The most impressive responses have occurred in children and adults with B cell acute lymphocytic leukemia (B-ALL), where complete response rates of $70-90 \%$ have been reported $[56 \bullet \bullet, 57 \bullet \bullet, 67 \bullet]$. Studies in adult B cell lymphoma and chronic lymphocytic leukemia (CLL) trials have posted lower but still impressive response rates $[65,68]$. Specific response rates reported in these early trials should be interpreted with caution however, since most studies have excluded patients whose engineered CAR product does not meet pre-established criteria for release, and excluded subjects whose disease progressed during the interim between apheresis and product generation. One study provided a true intent-to-treat complete response rate of $70 \%$ in refractory B-ALL [56••]. This trial also demonstrated $90 \%$ feasibility of generating and delivering the prescribed dose of CD19-CAR T cells in heavily pretreated patients with refractory B-ALL, many of whom had already undergone one or two hematopoietic stem cell transplants [56••]. Thus, while these early impressive results make it clear that CD19-CAR therapy provides potent therapeutic effects against an array of B cell malignancies, results of formal phase II studies of CD19-CAR therapy are needed in order to accurately measure true response rates to CD19-CAR therapy across diseases and across platforms.

Most CD19-CAR T cell protocols administer relatively low cell doses, in the range of $10^{7}-10^{8}$ CAR T cells, which undergo dramatic expansion in vivo and can eradicate large disease burdens. Indeed, the typical CD19-CAR T cell dose range is approximately two logs lower than the $\mathrm{T}$ cell doses administered in the context of adoptive immunotherapy using tumor infiltrating lymphocytes [69] and substantially lower than the dose of $\mathrm{T}$ cells administered in clinical trials using genetically engineered, affinity enhanced $\mathrm{T}$ cell receptors [70]. The difference in dose necessary for effective expansion in vivo likely relates to the fact that modern CARs incorporate a costimulatory domain, which enhances in vivo expansion and therefore enhances potency [52•]. Indeed, administration of $10^{10}$ CAR-transduced T cells with specificity for Her2Neu and incorporating both a CD28 and a 4-1BB endodomain was fatal, likely due to massive cytokine release syndrome [71]. Thus, on a cell per cell basis, the potency of CARs incorporating costimulatory domains is vastly greater than the potency of other adoptive cell therapies studied thus far. The lower total dose of T cells needed for efficacy has had substantial practical implications for simplifying and shortening the processes needed to generate CAR T cell grafts compared to other adoptive cell therapy products.

Animal studies clearly demonstrate the importance of lymphodepletion in supporting expansion of adoptively transferred $\mathrm{T}$ cells through the induction of elevated levels of homeostatic factors such as IL-7, which support the infused CAR T cells $[72,73]$. In addition, such regimens transiently diminish regulatory $\mathrm{T}$ cells, may augment innate immunity as a result of damage to the gut epithelium, may alter myeloid suppressor populations, and may allow enhanced penetration into the tumor bed, especially in the setting of solid tumors $[74,75]$. Numerous uncontrolled clinical studies provide data consistent with a beneficial effect of lymphodepletion prior to adoptive cell therapy for cancer. For example, three CLL patients treated with CD19-CAR T cells without a preparative regimen had no response, while three of four subsequently treated patients who received cyclophosphamide prior to cell infusion had significant responses [76]. Similar results have been reported in studies of adoptive immunotherapy using tumor infiltrating lymphocytes for melanoma [77]. Lymphodepleting regimens have varied widely across trials and it remains unknown whether one regimen is superior to another, or whether increasing dose intensity in the lymphopreparative regimen impacts response rate to CD19CAR therapy. Relatively low doses of chemotherapy appear sufficient for hematologic malignancies [56••]; however, higher doses of chemotherapy have often been administered in the setting of CAR therapy for lymphoma [68]. It is important to note that short-term response rates in clinical trials incorporating a dose-intensive lymphopreparative regimen should be interpreted with caution, since agents utilized in most preparative regimens are also directly active against B cell malignancies and could impact response rates directly.

All but two clinical trials of CD19-CAR T cells to date have utilized $\mathrm{T}$ cell grafts engineered from autologous $\mathrm{T}$ cells, regardless of whether the recipient has previously undergone allogeneic hematopoietic stem cell transplantation (HSCT). However, it is well recognized that patients relapsing after an allogeneic HSCT often have dysfunctional and few T cells, potentially diminishing the efficacy of CAR therapy in this setting. A trial by Cruz et al. administered donor-derived, viral-specific T cells engineered to express a CD19-CAR incorporating the CD28 costimulatory domain post-transplant without a lymphopreparative regimen. Objective responses 
were observed in two of six patients with evaluable disease at the time of treatment and there was no evidence for graftversus-host disease (GVHD) [78]. A second trial administered polyclonal donor-derived CD19-CAR T cells to allogeneic HSCT recipients post-relapse, also in the absence of a lymphodepleting preparative regimen. Despite the fact that potentially alloreactive, non-tolerized $\mathrm{T}$ cells of unknown specificity were infused directly to the recipient, no significant GVHD occurred, and three of ten patients showed evidence of an objective response [79]. These results suggest that donorderived CD19-CAR therapy may provide an option for patients following allogeneic HSCT, although it remains unclear whether the relatively low response rates observed in these series relates to the absence of a lymphopreparative regimen, and whether efficacy and/or safety might be modulated by administering such a regimen in this setting.

\section{Impact of Costimulatory Domain on CAR Persistence}

In clinical results reported thus far, response rates appear similar regardless of whether the CD19-CAR transgene is inserted via a lentiviral versus a retroviral vector, and similar response rates have been observed using CD19-CARs incorporating the FMC63 scFv $[56 \bullet \bullet, 57 \bullet \bullet, 80]$ versus the $\mathrm{SJ} 25 \mathrm{C} 1 \mathrm{scFv}$ [67•]. In contrast, emerging clinical results have identified distinctions in behavior between CD19-CARs incorporating a CD28 costimulatory domain (e.g., CD19.28.z) compared to those incorporating a 4-1BB domain (CD19.BB.z). In general, CD19.28.z undergo dramatic early expansion, often associated with early cytokine release syndrome and high response rates $[56 \bullet \bullet, 67 \bullet, 80]$. However, such CARs rarely persist longterm and recovery of normal B cells within $2-3$ months is typically observed. CD19.BB.z CARs incorporating the 4$1 \mathrm{BB}$ endodomain also undergo dramatic expansion, although the time to peak expansion appears slower and peak levels measured by PCR appear to be lower than observed in clinical trials using the CD19.28.z CARs [57••]. Furthermore, CD19.BB.z CAR T cells often persist for months to years, resulting in profound and prolonged $\mathrm{B}$ cell aplasia [57••]. Thus far, clinical results are not mature enough to determine whether the prolonged persistence of the CD19.BB.z CAR translates into improved cancer control in the long-term and whether this varies with disease. Such questions are critical to address in the coming years.

\section{Toxicity of CD19-CAR Therapy}

The most notable and frequent adverse event of CD19-CAR T cell therapy is cytokine release syndrome (CRS), which may range from a simple fever and constitutional symptoms to difficult-to-control hypotension requiring multiple vasopressors, respiratory failure, end-organ damage, or death. In typical cases, multiple inflammatory cytokines are elevated during the peak of symptoms, with levels of IL-6 and IFN $\gamma$ correlating with severity $\left[56^{\circ} \cdot\right.$. The syndrome appears to be effectively treated with immunosuppression, most commonly tocilizumab (an anti-IL6R antibody) or corticosteroids [57 ••, 66, $67 \cdot, 81]$. Current concepts hold that it is important to scale interventions to the severity of the syndrome, to minimize risks of excessive toxicity while maximizing the chance for therapeutic benefit from the CAR therapy. Several groups have demonstrated an important role for tumor burden in increasing the risk for severe cytokine release syndrome [56••, $57 \bullet \bullet$ ], raising the prospect that incorporation of CD19-CAR therapy into regimens where disease burdens are lower at the time of treatment may abrogate this toxicity altogether. Because multiple different grading systems have been used to assess severity of cytokine release syndrome, it has been difficult to compare the incidence and severity of this syndrome across CAR platforms. Recently, a multi-institutional consensus paper was published with the goal of establishing a standardized grading system linked to a treatment algorithm [81]. Harmonized grading systems for this novel toxicity would allow results of treatment interventions to be compared across institutions and clinical trials, and help to ensure the safety of this therapy as it is exported to larger numbers of institutions.

Neurotoxicity is another notable adverse event of CD19CAR T cell therapy. Visual hallucinations, dysmetria, ataxia, temporary aphasia, and seizures have been reported [56••, $57 \bullet \bullet, 68]$, all of which are typically fully reversible within hours to days. The basis for the toxicity remains unclear. While low-level CD19 expression has been reported on neuronal cells by immunohistochemistry [82], surface expression has not been validated. Furthermore, on-target, off-tumor $\mathrm{T}$ cell cytotoxicity of neuronal cells appears unlikely given the general reversibility of the neurologic symptoms. Alternatively, high levels of inflammatory cytokines could account for these symptoms. Elevated levels of inflammatory cytokines are present in the CSF of patients with CRS following CD19-CAR therapy [81] and IL-6 has been directly implicated in neurotoxicity [83, 84].

\section{Challenges and Opportunities}

\section{Multiple Dosing Strategies and CAR Immunogenicity}

Experience with cell-based therapy for melanoma has demonstrated that effective antitumor immune responses often manifest over the course of many months [85]. Similarly, while impressive anti-leukemic effects of CD19-CAR therapy are often observed within 28 days of treatment, many investigators believe that long-term disease control and/or cure require long-term immune pressure. One potential approach to apply persistent immune pressure utilizing CAR T cells is administration of multiple doses. However, several groups have 
measured T cell-mediated anti-CAR immune responses following CAR therapy, and such responses may preclude the effectiveness of multiple dosing regimens [56••, 86-88]. Indeed, results with multiple dosing strategies using CAR expressing $T$ cells have been disappointing thus far. In the report of Lee et al., three patients were treated with a second dose of CD19-CAR T cells for residual or recurrent CD19+ ALL following an initial dose of CD19-CARs and none responded [56••]. In another report, mesothelin-CARs were administered repeatedly and one patient experienced anaphylaxis following the third dose [89]. Many of these patients were highly immunocompromised, suggesting that CAR T cell therapies are sufficiently immunogenic to induce anti-CAR immunity even in such a setting. The molecular basis for immunogenicity of CAR T cells has not been systematically mapped thus far; however, most current CARs under study utilize a murinebased $\mathrm{scFv}$, which is a likely candidate for the target of antiCAR T cell immunity. For this reason, novel CARs currently being developed are often utilizing humanized or fully human binders [15]. Alternatively, junctions between the costimulatory domain and $\mathrm{CD} 3 \mathrm{z}$, or the $\mathrm{scFv}$ and the transmembrane domain, also represent "neoantigens" and could contribute to immunogenicity.

\section{CARs for Solid Tumors: Target Selection}

A major factor in the success of CAR therapy for B cell malignancies is that normal tissue expression of CD19 is limited to B cells. CAR-induced B cell depletion appears to be adequately managed, even in the long-term, with replacement immunoglobulin therapy [57••]. Unfortunately, most cell surface molecules that are highly expressed on solid tumors are also expressed to varying degrees on normal tissues, and thus do not have as favorable of expression profiles as CD19. A primary challenge facing CAR therapy for solid tumors will be the identification of antigens that can be safely targeted. Pertinent to this issue is a deficit in our understanding of the degree to which low level antigen expression on normal tissues poses a risk in the context of CAR therapy. Emerging data from several sources provide increasing insights into this important problem.

On-target toxicity related to CAR therapy is most well documented from studies of a CAR targeting carbonic anhydrase IX (CAIX), which is highly expressed on renal cell carcinoma as well as normal bile duct epithelium. An initial report of three patients treated with high doses $\left(1 \times 10^{9}\right)$ of first generation CAIX-CAR T cells reported reversible, severe (grade 34) hepatitis following CAR infusion [90]. A follow-up study provided histologic evidence of CAR infiltration at sites of inflammation and also demonstrated that pre-treatment with an unconjugated anti-CAIX mAb prevented liver toxicity in patients receiving similar doses of CAIX-CAR T cells [86]. As discussed above, anti-CAR immune responses were observed in patients in this trial; however interestingly, such immune responses did not occur in patients pretreated with anti-CAIX $\mathrm{mAb}[86]$.

Studies targeting GD2, a ganglioside expressed on neuroblastoma, some sarcomas and melanomas, and on peripheral nerves at low levels [91], have yielded a different experience. Treatment of children with anti-GD2 mAb therapy typically results in severe, temporary, neuropathic pain, presumably resulting from complement activation at the site of peripheral nerves [92]. In contrast, administration of a first generation GD2-CAR T cells without lymphodepletion demonstrated a favorable safety profile with no evidence for neurotoxicity. Eleven children with high risk or refractory neuroblastoma were treated with a first generation CAR targeting the disialoganglioside GD2. Half of eight evaluable patients had objective responses with one complete response [31], with GD2-CAR detected in surviving patients up to 192 weeks after infusion $[93 \cdot \bullet]$. Clinical trials of a third generation GD2-CAR for osteosarcoma and neuroblastoma administered following lymphodepletion are underway (NCT02107963, NCT01822652, NCT01953900), and no evidence for neurotoxicity has been reported.

A third scenario, as discussed above, involved administration of very high doses of CAR T cells expressing a third generation Her2Neu-CAR following lymphodepletion, which resulted in fatal toxicity with onset of symptoms within $30 \mathrm{~min}$ of infusion [71]. Initial reports implicated low-level antigen expression on normal tissues in the toxicity observed. However, a subsequent interpretation was that this toxicity represented cytokine release syndrome related to the high T cell dose, rather than on-target, off-tumor toxicity. On this basis, a follow-up study was performed using a second generation Her2Neu-CAR with careful dose escalation. Results of this recently published study demonstrate that administration of second generation anti-Her2Neu CAR T cells at doses up to $1 \times 10^{6} / \mathrm{m}^{2}$ resulted in significant expansion and persistence without evidence of toxicity [94]. Studies are ongoing to determine whether this favorable safety profile observed using the Her2Neu-CAR persists following a lymphodepleting preparative regimen. In summary, while there is clear evidence that normal tissue expression of a CAR target (e.g., CAIX) can result in substantial toxicity, some targets expressed at low levels on normal tissues have not resulted in autoimmune toxicity. More work is necessary to better understand the degree to which low-level expression of target antigens, on either normal or malignant tissues, serve as effective targets for CAR therapy.

\section{Regional Delivery and Approaches to Enhance Tumor Trafficking}

One approach to potentially prevent systemic off-tumor, ontarget cytotoxicity of solid tumor CARs, and to enhance 
exposure within the tumor microenvironment, is to deliver CARs regionally. An increasing number of groups have begun investigating such an approach. Her2Neu is highly expressed in glioblastoma and other malignant CNS tumors, and an ongoing study of intracranial injection of Her2Neu-CAR T cells for glioblastoma is underway (NCT02442297). Another group is investigating intratumoral delivery of Her2NeuCAR T cells that expand preferentially with IL-4 [95] for recurrent head and neck squamous cell carcinoma (NCT0181323). Intrapleural delivery of mesothelin CAR T cells in mesothelioma has shown promise in preclinical models [96] and is currently being tested in a clinical trial [75]. Regional delivery may require significantly lower doses of cells and result in less systemic exposure, thereby minimizing toxicity while maximizing antitumor response.

Other groups have attempted to improve tumor trafficking by modulating chemokines and/or incorporating chemokine receptors into CAR vectors. For example, neuroblastoma and other tumors secrete CCL2. Tumor cell infiltration by GD2CAR T cells in pre-clinical models increased dramatically upon co-expression of CCR2, the receptor for CCL2, and mediated increased cytotoxicity [97]. Thus, exploiting tumor-secreted factors, many of which are classically thought to be inhibitory, by incorporating their receptors into the CAR construct is another way to potentially augment CAR $\mathrm{T}$ cell function.

\section{Conclusions}

Adoptive T cell immunotherapy with CD19-directed CAR expressing $\mathrm{T}$ cells has shown unprecedented response rates as a single therapeutic maneuver in patients with refractory B lymphoblastic leukemia. Impressive response rates have also been observed in other B cell malignancies. This success resulted from over 20 years of optimizing the composition of such receptors, though our understanding of the optimal approach to engineering these receptors continues to evolve. Numerous challenges remain in this field, as investigators seek to expand the repertoire of effective CAR therapies to other hematologic malignancies and to solid tumors. Ultimately, the full potential of this field can only be realized by careful basic and clinical studies that can identify optimal methods for CAR engineering, safe and effective antigens for targeting, and clinical approaches to deliver the therapy most safely and most effectively.

Acknowledgments Daniel W. Lee is supported by the St. Baldrick's Foundation with generous support from the Hope from Harper Fund.

\section{Compliance with Ethical Standards}

Conflict of Interest Adrienne H. Long and Daniel W. Lee declare that they have no conflict of interest.

Crystal L. Mackall reports grants from Opus Incorporated and has a patent on the CD22-CAR with royalties paid to Juno Therapeutics.
Human and Animal Rights and Informed Consent This article does not contain primary data from any studies with human or animal subjects.

\section{References}

Papers of particular interest, published recently, have been highlighted as:

- Of importance

•- Of major importance

1. Gross G, Gorochov G, Waks T, Eshhar Z. Generation of effector T cells expressing chimeric T cell receptor with antibody type-specificity. Transplant Proc. 1989;21(1 Pt 1):127-30.

2. Gross G, Waks T, Eshhar Z. Expression of immunoglobulin-T-cell receptor chimeric molecules as functional receptors with antibodytype specificity. Proc Natl Acad Sci U S A. 1989;86(24):10024-8.

3. Irving BA, Weiss A. The cytoplasmic domain of the T cell receptor zeta chain is sufficient to couple to receptor-associated signal transduction pathways. Cell. 1991;64(5):891-901.

4. Eshhar Z, Waks T, Gross G, Schindler DG. Specific activation and targeting of cytotoxic lymphocytes through chimeric single chains consisting of antibody-binding domains and the gamma or zeta subunits of the immunoglobulin and T-cell receptors. Proc Natl Acad Sci U S A. 1993;90(2):720-4.

5. Brown CE, Starr R, Aguilar B, Shami AF, Martinez C, D'Apuzzo $\mathrm{M}$, et al. Stem-like tumor-initiating cells isolated from IL13R $\alpha 2$ expressing gliomas are targeted and killed by IL13-zetakineredirected T cells. Clin Cancer Res. 2012;18(8):2199-209.

6. Kahlon KS, Brown C, Cooper LJ, Raubitschek A, Forman SJ, Jensen MC. Specific recognition and killing of glioblastoma multiforme by interleukin 13-zetakine redirected cytolytic T cells. Cancer Res. 2004;64(24):9160-66.

7. Stastny MJ, Brown CE, Ruel C, Jensen MC. Medulloblastomas expressing il13r [alpha] 2 are targets for ill3-zetakine+cytolytic T cells. J Pediatr Hematol Oncol. 2007;29(10):669-77.

8. Niederman TMJ, Ghogawala Z, Carter BS, Tompkins HS, Russell MM, Mulligan RC. Antitumor activity of cytotoxic T lymphocytes engineered to target vascular endothelial growth factor receptors. Proc Natl Acad Sci. 2002;99(10):7009-14.

9. Pameijer CRJ, Navanjo A, Meechoovet B, Wagner JR, Aguilar B, Wright CL, et al. Conversion of a tumor-binding peptide identified by phage display to a functional chimeric $\mathrm{T}$ cell antigen receptor. Cancer Gene Ther. 2006;14(1):91-7.

10. Muniappan A, Banapour B, Lebkowski J, Talib S. Ligand-mediated cytolysis of tumor cells: use of heregulin- $\zeta$ chimeras to redirect cytotoxic T lymphocytes. Cancer Gene Ther. 2000;7(1):128.

11. Brown CE, Badie B, Barish ME, Weng L, Ostberg JR, Chang WC, Naranjo A, Starr R, Wagner J, Wright C, et al. Bioactivity and safety of IL13Ralpha2-redirected chimeric antigen receptor CD8+ T cells in patients with recurrent glioblastoma. Clin Cancer Res. 2015.

12. Turatti F, Figini M, Balladore E, Alberti P, Casalini P, Marks JD, et al. Redirected activity of human antitumor chimeric immune receptors is governed by antigen and receptor expression levels and affinity of interaction. J Immunother. 2007;30(7):684-93.

13. Hudecek M, Lupo-Stanghellini M-T, Kosasih PL, Sommermeyer $\mathrm{D}$, Jensen MC, Rader C, et al. Receptor affinity and extracellular domain modifications affect tumor recognition by ROR1-specific chimeric antigen receptor T cells. Clin Cancer Res. 2013;19(12): 3153-64.

14. Chmielewski M, Hombach A, Heuser C, Adams GP, Abken H. T cell activation by antibody-like immunoreceptors: increase in affinity of the single-chain fragment domain above threshold does not 
increase $\mathrm{T}$ cell activation against antigen-positive target cells but decreases selectivity. J Immunol. 2004;173(12):7647-53.

15. Haso W, Lee DW, Shah NN, Stetler-Stevenson M, Yuan CM, Pastan IH, Dimitrov DS, Morgan RA, FitzGerald DJ, Barrett DM, et al. Anti-CD22-chimeric antigen receptors targeting B-cell precursor acute lymphoblastic leukemia. Blood. 2013;121(7):116574.

16. Hombach AA, Schildgen V, Heuser C, Finnern R, Gilham DE, Abken $\mathrm{H}$. T cell activation by antibody-like immunoreceptors: the position of the binding epitope within the target molecule determines the efficiency of activation of redirected $\mathrm{T}$ cells. $\mathrm{J}$ Immunol. 2007;178(7):4650-57.

17. James SE, Greenberg PD, Jensen MC, Lin Y, Wang J, Till BG, et al. Antigen sensitivity of CD22-specific chimeric TCR is modulated by target epitope distance from the cell membrane. J Immunol. 2008;180(10):7028-38.

18.• Long AH, Haso WM, Shern JF, Wanhainen KM, Murgai M, Ingaramo M, Smith JP, Walker AJ, Kohler ME, Venkateshwara VR, et al. 4-1BB costimulation ameliorates $\mathrm{T}$ cell exhaustion induced by tonic signaling of chimeric antigen receptors. Nat Med. 2015; advance online publication. This report identified early exhaustion due to tonic, antigen-independent CAR signaling as an important cause of poor CAR T cell function and identified a critical role for 4-1BB costimulation in preventing $T$ cell exhaustion.

19. Nieba L, Honegger A, Krebber C, Pluckthun A. Disrupting the hydrophobic patches at the antibody variable/constant domain interface: improved in vivo folding and physical characterization of an engineered scFv fragment. Protein Eng. 1997;10(4):435-44.

20. Dolezal O, De Gori R, Walter M, Doughty L, Hattarki M, Hudson PJ, et al. Single-chain Fv multimers of the anti-neuraminidase antibody NC10: the residue at position 15 in the $\mathrm{V}(\mathrm{L})$ domain of the scFv-0 (V(L)-V(H)) molecule is primarily responsible for formation of a tetramer-trimer equilibrium. Protein Eng. 2003;16(1):47-56.

21. Whitlow M, Filpula D, Rollence ML, Feng SL, Wood JF. Multivalent Fvs: characterization of single-chain Fv oligomers and preparation of a bispecific Fv. Protein Eng. 1994;7(8):101726.

22. Frigault MJ, Lee J, Basil MC, Carpenito C, Motohashi S, Scholler J, et al. Identification of chimeric antigen receptors that mediate constitutive or inducible proliferation of T cells. Cancer Immunol Res. 2015;3(4):356-67.

23. Bridgeman J, Hawkins R, Hombach A, Abken H, Gilham D. Building better chimeric antigen receptors for adoptive T cell therapy. Curr gene Ther. 2010;10(2):77-90. Thorough review of early CAR engineering optimization studies.

24. Moritz D, Groner B. A spacer region between the single chain antibody-and the $\mathrm{CD} 3$ zeta-chain domain of chimeric T cell receptor components is required for efficient ligand binding and signaling activity. Gene Ther. 1995;2(8):539-46.

25. Patel S, Moskalenko M, Smith D, Maske B, Finer M, McArthur J. Impact of chimeric immune receptor extracellular protein domains on T cell function. Gene Ther. 1999;6(3):412-19.

26. Jonnalagadda M, Mardiros A, Urak R, Wang X, Hoffman LJ, Bernanke A, Chang W-C, Bretzlaff W, Starr R, Priceman S. Chimeric antigen receptors with mutated $\mathrm{IgG} 4 \mathrm{Fc}$ spacer avoid $\mathrm{Fc}$ receptor binding and improve $\mathrm{T}$ cell persistence and anti-tumor efficacy. Molecular Therapy 2014.

27. Hudecek M, Sommermeyer D, Kosasih PL, Silva-Benedict A, Liu $\mathrm{L}$, Rader $\mathrm{C}$, et al. The nonsignaling extracellular spacer domain of chimeric antigen receptors is decisive for in vivo antitumor activity. Cancer Immunol Res. 2015;3(2):125-35. This report identified that CAR spacers derived from IgG constant domains can limit CAR efficacy through interactions with myeloid cells in vivo, leading to CAR T cell activation induced cell death
28. Brentjens RJ, Latouche J-B, Santos E, Marti F, Gong MC, Lyddane C, et al. Eradication of systemic B-cell tumors by genetically targeted human $\mathrm{T}$ lymphocytes co-stimulated by CD80 and interleukin-15. Nat Med. 2003;9(3):279-86.

29. Daly T, Royal RE, Kershaw MH, Treisman J, Wang G, Li W, et al. Recognition of human colon cancer by $\mathrm{T}$ cells transduced with a chimeric receptor gene. Cancer Gene Ther. 2000;7(2):284-91.

30. Altenschmidt $U$, Klundt E, Groner B. Adoptive transfer of in vitrotargeted, activated $\mathrm{T}$ lymphocytes results in total tumor regression. $\mathrm{J}$ Immunol. 1997;159(11):5509-15.

31. Pule MA, Savoldo B, Myers GD, Rossig C, Russell HV, Dotti G, et al. Virus-specific $T$ cells engineered to coexpress tumor-specific receptors: persistence and antitumor activity in individuals with neuroblastoma. Nat Med. 2008;14(11):1264-70.

32. Kershaw MH, Westwood JA, Parker LL, Wang G, Eshhar Z, Mavroukakis SA, et al. A phase I study on adoptive immunotherapy using gene-modified $\mathrm{T}$ cells for ovarian cancer. Clin Cancer Res. 2006;12(20):6106-15.

33. Weijtens ME, Willemsen RA, Valerio D, Stam K, Bolhuis R. Single chain Ig/gamma gene-redirected human $\mathrm{T}$ lymphocytes produce cytokines, specifically lyse tumor cells, and recycle lytic capacity. J Immunol. 1996;157(2):836-43.

34. Hombach A, Muche J, Gerken M, Gellrich S, Heuser C, Pohl C, et al. T cells engrafted with a recombinant anti-CD30 receptor target autologous CD30 (+) cutaneous lymphoma cells. Gene Ther. 2001;8(11):891-95.

35. Ren-Heidenreich L, Hayman G, Trevor K. Specific targeting of EGP-2+ tumor cells by primary lymphocytes modified with chimeric T cell receptors. Hum Gene Ther. 2000;11(1):9-19.

36. Mezzanzanica D, Canevari S, Mazzoni A, Figini M, Colnaghi MI, Waks T, et al. Transfer of chimeric receptor gene made of variable regions of tumor-specific antibody confers anticarbohydrate specificity on T cells. Cancer Gene Ther. 1997;5(6):401-7.

37. Brocker $\mathrm{T}$. Chimeric $\mathrm{Fv}_{\mathrm{V}} \zeta$ or $\mathrm{Fv}_{\mathrm{V}-\varepsilon} \varepsilon$ receptors are not sufficient to induce activation or cytokine production in peripheral $\mathrm{T}$ cells. Blood. 2000;1999-2001.

38. Brocker T, Karjalainen K. Adoptive tumor immunity mediated by lymphocytes bearing modified antigen-specific receptors. Adv Immunol. 1998;68:257-69.

39. Park JR, DiGiusto DL, Slovak M, Wright C, Naranjo A, Wagner J, et al. Adoptive transfer of chimeric antigen receptor re-directed cytolytic T lymphocyte clones in patients with neuroblastoma. Mol Ther. 2007;15(4):825-33.

40. Sadelain M, Brentjens R, Rivière I. The basic principles of chimeric antigen receptor design. Cancer Discovery. 2013;3(4):388-98.

41. Pulè MA, Straathof KC, Dotti G, Heslop HE, Rooney CM, Brenner MK. A chimeric T cell antigen receptor that augments cytokine release and supports clonal expansion of primary human $\mathrm{T}$ cells. Mol Ther. 2005;12(5):933-41.

42. Hombach AA, Heiders J, Foppe M, Chmielewski M, Abken H. OX40 costimulation by a chimeric antigen receptor abrogates CD28 and IL-2 induced IL-10 secretion by redirected CD4+ T cells. Oncoimmunol. 2012;1(4):458-66.

43. Song D-G, Ye Q, Poussin M, Harms GM, Figini M, Powell DJ. CD27 costimulation augments the survival and antitumor activity of redirected human T cells in vivo. Blood. 2012;119(3):696-706.

44. Guedan S, Chen X, Madar A, Carpenito C, McGettigan SE, Frigault MJ, Lee J, Posey Jr AD, Scholler J, Scholler N. ICOSbased chimeric antigen receptors program bipolar TH17/TH1 cells. Blood. 2014.

45. Finney HM, Lawson AD, Bebbington CR, Weir ANC. Chimeric receptors providing both primary and costimulatory signaling in $\mathrm{T}$ cells from a single gene product. J Immunol. 1998;161(6):2791-97.

46. Maher J, Brentjens RJ, Gunset G, Rivière I, Sadelain M. Human Tlymphocyte cytotoxicity and proliferation directed by a single chimeric TCRC/CD28 receptor. Nat Biotechnol. 2002;20(1):70-5. 
47. Geiger TL, Nguyen P, Leitenberg D, Flavell RA. Integrated src kinase and costimulatory activity enhances signal transduction through single-chain chimeric receptors in T lymphocytes. Blood. 2001;98(8):2364-71.

48. Hombach A, Wieczarkowiecz A, Marquardt T, Heuser C, Usai L, Pohl C, et al. Tumor-specific $\mathrm{T}$ cell activation by recombinant immunoreceptors: $\mathrm{CD} 3 \zeta$ signaling and $\mathrm{CD} 28$ costimulation are simultaneously required for efficient IL-2 secretion and can be integrated into one combined $\mathrm{CD} 28 / \mathrm{CD} 3 \zeta$ signaling receptor molecule. J Immunol. 2001;167(11):6123-31.

49. Haynes NM, Trapani JA, Teng MW, Jackson JT, Cerruti L, Jane SM, et al. Single-chain antigen recognition receptors that costimulate potent rejection of established experimental tumors. Blood. 2002;100(9):3155-63.

50. Kowolik CM, Topp MS, Gonzalez S, Pfeiffer T, Olivares S, Gonzalez N, et al. CD28 costimulation provided through a CD19specific chimeric antigen receptor enhances in vivo persistence and antitumor efficacy of adoptively transferred $\mathrm{T}$ cells. Cancer Res. 2006;66(22):10995-1004.

51. Haynes NM, Snook MB, Trapani JA, Cerruti L, Jane SM, Smyth MJ, et al. Redirecting mouse CTL against colon carcinoma: superior signaling efficacy of single-chain variable domain chimeras containing TCR- $\zeta$ vs FeعRI- $\gamma$. J Immunol. 2001;166(1):182-87.

52. Savoldo B, Ramos CA, Liu E, Mims MP, Keating MJ, Carrum G, et al. CD28 costimulation improves expansion and persistence of chimeric antigen receptor-modified $\mathrm{T}$ cells in lymphoma patients. $\mathrm{J}$ Clin Invest. 2011;121(5):1822-26. This report provides direct comparison of persistence of first generation and second generation CAR T cells in patients.

53. Zhao Y, Wang QJ, Yang S, Kochenderfer JN, Zheng Z, Zhong X, et al. A herceptin-based chimeric antigen receptor with modified signaling domains leads to enhanced survival of transduced $\mathrm{T}$ lymphocytes and antitumor activity. J Immunol. 2009;183(9):5563-74.

54. Zhong X-S, Matsushita M, Plotkin J, Riviere I, Sadelain M. Chimeric antigen receptors combining 4-1BB and CD28 signaling domains augment PI3kinase/AKT/Bcl-XL activation and CD8+ T cell-mediated tumor eradication. Mol Ther. 2009;18(2):413-20.

55. Kunkele A, Johnson AJ, Rolczynski LS, Chang CA, Hoglund V, Kelly-Spratt KS, et al. Functional tuning of CARs reveals signaling threshold above which CD8+CTL antitumor potency is attenuated due to cell Fas-FasL-dependent AICD. Cancer Immunol Res. 2015;3(4):368-79.

$56 . \bullet$ Lee DW, Kochenderfer JN, Stetler-Stevenson M, Cui YK, Delbrook C, Feldman SA, et al. T cells expressing CD19 chimeric antigen receptors for acute lymphoblastic leukaemia in children and young adults: a phase 1 dose-escalation trial. Lancet. 2015;385(9967):517-28. This is the only intent-to-treat trial of CD19-CAR reported and demonstrated a $70 \% \mathrm{CR}$ rate and a $90 \%$ feasibility rate.

57.• Maude SL, Frey N, Shaw PA, Aplenc R, Barrett DM, Bunin NJ, et al. Chimeric antigen receptor $t$ cells for sustained remissions in leukemia. N Engl J Med. 2014;371(16):1507-17. This report showed a very high $(>90 \%)$ response rate in a series of patients treated with CD19-CAR therapy.

58. Topp MS, Gökbuget N, Zugmaier G, Klappers P, Stelljes M, Neumann S, Viardot A, Marks R, Diedrich H, Faul C, et al. Phase II trial of the anti-CD19 bispecific T cell-engager blinatumomab shows hematologic and molecular remissions in patients with relapsed or refractory B-precursor acute lymphoblastic leukemia. Journal of Clinical Oncology. 2014.

59. Hegde M, Corder A, Chow KK, Mukherjee M, Ashoori A, Kew Y, et al. Combinational targeting offsets antigen escape and enhances effector functions of adoptively transferred T cells in glioblastoma. Mol Ther. 2013;21(11):2087-101. This report demonstrated the ability to prevent antigen-escape variants following CAR treatments by targeting two antigens simultaneously.
60. Grada Z, Hegde M, Byrd T, Shaffer DR, Ghazi A, Brawley VS, et al. TanCAR: a novel bispecific chimeric antigen receptor for cancer immunotherapy. Mol Ther Nucleic Acids. 2013;2(7), e105. This report demonstrated the ability to target two antigens through a bispecific, tandem CAR.

61. Fedorov VD, Themeli M, Sadelain M. PD-1- and CTLA-4-based inhibitory chimeric antigen receptors (iCARs) divert off-target immunotherapy responses. Sci Transl Med. 2013;5(215):215ra172.

62. Kloss CC, Condomines M, Cartellieri M, Bachmann M, Sadelain M. Combinatorial antigen recognition with balanced signaling promotes selective tumor eradication by engineered T cells. Nat Biotechnol. 2013;31(1):71-5. This report demonstrates proofof-principal for separation of $\mathrm{CD} 3 \zeta$ and costimulatory domains to enhance specificity of CAR T cells to tumor cells doublepositive for two antigens.

63. Lanitis E, Poussin M, Klattenhoff AW, Song D, Sandaltzopoulos R, June $\mathrm{CH}$, et al. Chimeric antigen receptor T cells with dissociated signaling domains exhibit focused antitumor activity with reduced potential for toxicity in vivo. Cancer Immunol Res. 2013;1(1):4353.

64. Kochenderfer JN, Wilson WH, Janik JE, Dudley ME, StetlerStevenson M, Feldman SA, et al. Eradication of B-lineage cells and regression of lymphoma in a patient treated with autologous $\mathrm{T}$ cells genetically engineered to recognize CD19. Blood. 2010;116(20):4099-102.

65. Porter DL, Levine BL, Kalos M, Bagg A, June CH. Chimeric antigen receptor-modified $\mathrm{T}$ cells in chronic lymphoid leukemia. $\mathrm{N}$ Engl J Med. 2011;365(8):725-33.

66. Grupp SA, Kalos M, Barrett D, Aplenc R, Porter DL, Rheingold $\mathrm{SR}$, et al. Chimeric antigen receptor-modified T cells for acute lymphoid leukemia. N Engl J Med. 2013;368(16):1509-18.

67. Davila ML, Riviere I, Wang X, Bartido S, Park J, Curran K, et al. Efficacy and toxicity management of 19-28z CAR T cell therapy in B cell acute lymphoblastic leukemia. Sci Transl Med. 2014;6(224): 224ra25. This report also showed a very high response rate to CD19-CAR in a series of adult patients treated for refractory BALL.

68. Kochenderfer JN, Dudley ME, Kassim SH, Somerville RPT, Carpenter RO, Stetler-Stevenson M, Yang JC, Phan GQ, Hughes MS, Sherry RM, et al. Chemotherapy-refractory diffuse large B-cell lymphoma and indolent B-cell malignancies can be effectively treated with autologous $\mathrm{T}$ cells expressing an anti-CD19 chimeric antigen receptor. J Clin Oncol. 2014.

69. Hinrichs CS, Rosenberg SA. Exploiting the curative potential of adoptive T-cell therapy for cancer. Immunol Rev. 2014;257(1): 56-71.

70. Robbins PF, Morgan RA, Feldman SA, Yang JC, Sherry RM, Dudley ME, et al. Tumor regression in patients with metastatic synovial cell sarcoma and melanoma using genetically engineered lymphocytes reactive with NY-ESO-1. J Clin Oncol. 2011;29(7): 917-24.

71. Morgan RA, Yang JC, Kitano M, Dudley ME, Laurencot CM, Rosenberg SA. Case report of a serious adverse event following the administration of $\mathrm{T}$ cells transduced with a chimeric antigen receptor recognizing ERBB2. Mol Ther. 2010;18(4):843-51.

72. Cui Y, Zhang H, Meadors J, Poon R, Guimond M, Mackall CL. Harnessing the physiology of lymphopenia to support adoptive immunotherapy in lymphoreplete hosts. Blood. 2009;114(18):383140.

73. Mackall CL, Fry TJ, Gress RE. Harnessing the biology of IL-7 for therapeutic application. Nat Rev Immunol. 2011;11(5):330-42.

74. Wrzesinski C, Paulos CM, Kaiser A, Muranski P, Palmer DC, Gattinoni L, et al. Increased intensity lymphodepletion enhances tumor treatment efficacy of adoptively transferred tumor-specific T cells. J Immunother. 2010;33(1):1-7. 
75. Klebanoff CA, Khong HT, Antony PA, Palmer DC, Restifo NP. Sinks, suppressors and antigen presenters: how lymphodepletion enhances $\mathrm{T}$ cell-mediated tumor immunotherapy. Trends Immunol. 2005;26(2):111-7.

76. Brentjens RJ, Davila ML, Riviere I, Park J, Wang X, Cowell LG, Bartido S, Stefanski J, Taylor C, Olszewska M. CD19-targeted T cells rapidly induce molecular remissions in adults with chemotherapy-refractory acute lymphoblastic leukemia. Sci Transl Med. 2013;5(177):177ra38-77ra38.

77. Dudley ME, Yang JC, Sherry R, Hughes MS, Royal R, Kammula $\mathrm{U}$, et al. Adoptive cell therapy for patients with metastatic melanoma: evaluation of intensive myeloablative chemoradiation preparative regimens. J Clin Oncol. 2008;26(32):5233-9.

78. Cruz CR, Micklethwaite KP, Savoldo B, Ramos CA, Lam S, Ku S, et al. Infusion of donor-derived CD19-redirected virus-specific T cells for B-cell malignancies relapsed after allogeneic stem cell transplant: a phase 1 study. Blood. 2013;122(17):2965-73.

79. Kochenderfer JN, Dudley ME, Carpenter RO, Kassim SH, Rose JJ, Telford WG, Hakim FT, Halverson DC, Fowler DH, Hardy NM, et al. Donor-derived CD19-targeted T cells cause regression of malignancy persisting after allogeneic hematopoietic stem cell transplantation. Blood. 2013;4129-39.

80. Kochenderfer JN, Yu Z, Frasheri D, Restifo NP, Rosenberg SA. Adoptive transfer of syngeneic $\mathrm{T}$ cells transduced with a chimeric antigen receptor that recognizes murine CD19 can eradicate lymphoma and normal B cells. Blood. 2010;116(19):3875-86.

81. Lee DW, Gardner R, Porter DL, Louis CU, Ahmed N, Jensen M, Grupp SA, Mackall CL. Current concepts in the diagnosis and management of cytokine release syndrome. 2014;188-95.

82. Uhlén M, Fagerberg L, Hallström BM, Lindskog C, Oksvold P, Mardinoglu A, Sivertsson Å, Kampf C, Sjöstedt E, Asplund A, et al. Tissue-based map of the human proteome. Science. 2015;347(6220).

83. Spooren A, Kolmus K, Laureys G, Clinckers R, De Keyser J, Haegeman G, et al. Interleukin-6, a mental cytokine. Brain Res Rev. 2011;67(1-2):157-83.

84. Weber J, Gunn H, Yang J, Parkinson D, Topalian S, Schwartzentruber D, et al. A phase I trial of intravenous interleukin- 6 in patients with advanced cancer. J Immunother Emphasis Tumor Immunol. 1994;15(4):292-302.

85. Robbins PF, Kassim SH, Tran TLN, Crystal JS, Morgan RA, Feldman SA, et al. A pilot trial using lymphocytes genetically engineered with an NY-ESO-1-reactive T-cell receptor: long-term follow-up and correlates with response. Clin Cancer Res. 2015;21(5):1019-27.

86. Lamers CHJ, Sleijfer S, van Steenbergen S, van Elzakker P, van Krimpen B, Groot C, et al. Treatment of metastatic renal cell carcinoma with CAIX CAR-engineered T cells: clinical evaluation and management of on-target toxicity. Mol Ther. 2013;21(4):904-12.

87. Lamers CHJ, Willemsen R, van Elzakker P, van SteenbergenLangeveld S, Broertjes M, Oosterwijk-Wakka J, Oosterwijk E,
Sleijfer S, Debets R, Gratama JW. Immune responses to transgene and retroviral vector in patients treated with ex vivo-engineered $\mathrm{T}$ cells. Blood. 2011;72-82.

88. Jensen MC, Popplewell L, Cooper LJ, DiGiusto D, Kalos M, Ostberg JR, et al. Antitransgene rejection responses contribute to attenuated persistence of adoptively transferred CD20/CD19specific chimeric antigen receptor redirected $\mathrm{T}$ cells in humans. Biol Blood Marrow Transplant. 2010;16(9):1245-56.

89. Maus MV, Haas AR, Beatty GL, Albelda SM, Levine BL, Liu X, et al. T cells expressing chimeric antigen receptors can cause anaphylaxis in humans. Cancer Immunol Res. 2013;1:26-31.

90. Lamers CH, Sleijfer S, Vulto AG, Kruit WH, Kliffen M, Debets R, et al. Treatment of metastatic renal cell carcinoma with autologous T-lymphocytes genetically retargeted against carbonic anhydrase IX: first clinical experience. J Clin Oncol. 2006;24(13):e20-2.

91. Alvarez-Rueda N, Desselle A, Cochonneau D, Chaumette T, Clemenceau B, Leprieur S, et al. A monoclonal antibody to Oacetyl-GD2 ganglioside and not to GD2 shows potent anti-tumor activity without peripheral nervous system cross-reactivity. PLoS One. 2011;6(9), e25220.

92. Navid F, Sondel PM, Barfield R, Shulkin BL, Kaufman RA, Allay JA, et al. Phase I trial of a novel anti-GD2 monoclonal antibody, Hu14.18K322A, designed to decrease toxicity in children with refractory or recurrent neuroblastoma. J Clin Oncol. 2014;32(14): 1445-52.

93.• Louis CU, Savoldo B, Dotti G, Pule M, Yvon E, Myers GD, Rossig C, Russell HV, Diouf O, Liu E, et al. Antitumor activity and longterm fate of chimeric antigen receptor-positive $\mathrm{T}$ cells in patients with neuroblastoma. Blood. 2011;6050-56. This study provides most encouraging results to date with CAR $T$ cells targeting solid tumors, with 4 of 8 evaluable neuroblastoma patients having objective responses.

94. Ahmed N, Brawley VS, Hegde M, Robertson C, Ghazi A, Gerken $\mathrm{C}$, et al. Human epidermal growth factor receptor 2 (HER2)-specific chimeric antigen receptor-modified $\mathrm{T}$ cells for the immunotherapy of HER2-positive sarcoma. J Clin Oncol. 2015;33(15):1688-96.

95. van Schalkwyk MCI, Papa SE, Jeannon J-P, Urbano TG, Spicer JF, Maher J. Design of a phase I clinical trial to evaluate intratumoral delivery of ErbB-targeted chimeric antigen receptor T-cells in locally advanced or recurrent head and neck cancer. Hum Gene Ther Clin Dev. 2013;24(3):134-42.

96. Adusumilli PS, Cherkassky L, Villena-Vargas J, Colovos C, Servais E, Plotkin J, Jones DR, Sadelain M. Regional delivery of mesothelin-targeted CAR T cell therapy generates potent and long-lasting CD4-dependent tumor immunity. Sci Transl Med. 2014;261ra151-261ra151.

97. Craddock JA, Lu A, Bear A, Pule M, Brenner MK, Rooney CM, Foster AE. Enhanced tumor trafficking of GD2 chimeric antigen receptor T cells by expression of the chemokine receptor CCR2b. J Immunother (Hagerstown, Md: 1997). 2010;33(8):780. 